\title{
Pengaruh Pemberian Pursed Lip-Breathing, Diaphragmatic Breathing, dan Upper Limb Stretching Terhadap Skala Dispnea pada Pasien PPOK
}

\author{
Imron Rosyadi ${ }^{\mathrm{a}}$, Defriman Djafri ${ }^{\mathrm{b}}$, Dally Rahman ${ }^{\mathrm{c}}$ \\ ${ }^{a}$ Magister Keperawatan, Fakultas Keperawatan Universitas Andalas, Padang, 25163, Indonesia \\ ${ }^{b}$ Fakultas Kesehatan Masyarakat Universitas Andalas, Padang, 25163, Indonesia \\ 'Bagian Keperawatan Medikal Bedah, Fakultas Keperawatan Universitas Andalas, Padang, 25163, \\ Indonesia \\ e-mail korespondensi: imronrosyadigomugomu@gmail.com
}

\begin{abstract}
Respiratory muscle weakness in patients with Chronic Obstructive Pulmonary Disease (COPD) is a problem that can affect the patient's ability to conduct daily activities. The aim of this study to see the difference between the intervention group given the pursed-lip breathing exercises, diaphragmatic breathing, and upper limb stretching with the control group which not given therapy. 38 COPD patients were grouped into intervention groups $(n=18)$ and control group $(n=18)$ randomly. The intervention group was given pursed-lip breathing, diaphragmatic breathing, and upper limb stretching for 4 weeks as much as two times for each week, while the control group was not given exercise. The dyspnea scale was measured using the MRC Dyspnea Scale questionnaire and was categorized as mild (scale 1), medium (scale 2-3) and severe (scale 4-5). The result showed there was a difference in dyspnea ( $p$ value 0.008) for intervention group and there is no difference in the dyspnea for control group that was not given exercise ( $p$ value 0.655). In conclusion, pursed lip breathing, diaphragmatic breathing, and upper limb stretching can give more significant benefits when done sustainably, especially for COPD patients.
\end{abstract}

Keywords: COPD, dyspnea scale

\begin{abstract}
Abstrak
Kelemahan otot pernapasan pada pasien dengan Penyakit Paru Obstruktif Kronik (PPOK) merupakan permasalahan yang dapat mempengaruhi kemampuan pasien dalam melakukan aktivitas harian. Tujuan dari penelitian ini untuk melihat perbedaan antara kelompok intervensi yang diberikan latihan pursed lip breathing, diaphragmatic breathing, dan upper limb stretching dengan kelompok kontrol yang tidak diberikan terapi. 38 pasien PPOK dikelompokkan menjadi kelompok intervensi $(n=18)$ dan kelompok kontrol ( $\mathrm{n}=18)$. Kelompok intervensi diberikan latihan pursed lip breathing, diaphragmatic breathing, dan upper limb stretching selama 4 minggu sebanyak 2 kali dalam 1 minggu, sedangkan kelompok kontrol tidak diberikan latihan. Skala dispnea diukur menggunakan kuesioner MRC Dyspnea Scale dan dikategorikan menjadi ringan (skala 1), sedang (skala 2-3), dan berat (skala 4-5). Terdapat perbedaan dispnea ( $\mathrm{p}$ value 0,008) dan sekaligus tidak ada perbedaan dispnea pada kelompok kontrol yang tidak diberikan latihan ( $\mathrm{p}$ value 0,655 ). Pursed lip breathing, diaphragmatic breathing, dan upper limb stretching dapat memberikan manfaat yang lebih signifikan apabila dilakukan secara berkelanjutan, khususnya bagi pasien PPOK.
\end{abstract}

Kata Kunci: PPOK, Skala dispnea

\section{PENDAHULUAN}

Penurunan fungsi pernapasan yang terjadi pada pasien PPOK dapat dikaitkan dengan gaya hidup yang dijalani pasien PPOK sebelumnya. Gaya hidup yang tidak sehat dapat mempengaruhi fungsi otot pernapasan di masa yang akan datang (Langer et al., 2015). Penurunan fungsi pernapasan menyebabkan adanya peningkatan usaha dalam proses bernafas yang ditandai dengan sesak nafas yang dirasakan pasien PPOK (Russell, Ford, Barners, \& Russel, 2013).

Sesak nafas yang dirasakan pasien PPOK dapat menjadi permasalahan besar bagi pasien. Data yang didapatkan dari 
World Health Organization (WHO) (2016) dimana pada tahun 2015 diperkirakan sebanyak 3 juta orang yang meninggal dunia disebabkan oleh PPOK. Fenomena yang terjadi di Indonesia adalah sebanyak $3,7 \%$ penduduk Indonesia didiagnosa PPOK. Di Sumatera Barat berdasarkan data dari Dinas Kesehatan Propinsi Sumatera Barat dimana jumlah pasien PPOK pada tahun 2016 berjumlah 2.284 orang. Diperkirakan jumlah pasien yang mengidap PPOK akan terus bertambah setiap tahunnya (Tim Promosi Kesehatan Rumah Sakit (PKRS), 2017).

Beberapa upaya pengobatan sudah dilakukan dalam menanggapi angka kejadian PPOK yang semakin meningkat. Pengobatan PPOK yang diberikan masih menimbulkan gejala sisa bagi pasien (Mehani, 2017). Menurut Walters, Tan, White, \& Wood-Baker (2018) didapatkan tidak ada perbedaan gejala yang signifikan sejak pengobatan dimulai hingga 7 hari setelah pengobatan dilaksanakan. Gejala yang dirasakan pasien pada umumnya adalah batuk berdahak yang semakin parah pada saat pagi hari, sesak nafas, dan penurunan kemampuan atau ketahanan dalam melakukan aktivitas (Malini, Fatmadona, Rahman, \& Afriyanti, 2018).

Penurunan kemampuan dan ketahanan saat melakukan aktivitas dapat diperbaiki dengan melakukan latihan pernapasan secara rutin (Heydari, Farzad, \& Ahmadi Hosseini, 2015). Latihan pernapasan yang dapat dilakukan berupa pursed lip breathing, latihan pernapasan diafragma, dan dapat juga disertai dengan peregangan pada otot tubuh bagian atas (Amin \& Zedan, 2017; Zuwallack \& Celli, 2016).

\section{METODE}

Penelitian ini menggunakan Randomized Control Trial (RCT) dengan randomisasi pada saat pengambilan sampel (simple random sampling) dan pengelompokan subjek penelitian (allocation random). Pasien PPOK yang dijadikan sampel dalam penelitian ini merupakan pasien kunjungan poliklinik paru Rumah Sakit Paru Provinsi Sumatera Barat pada bulan Februari 2019. Persetujuan etik penelitian didapatkan pada tanggal 10 April 2019 di Komite Etik Fakultas Kedokteran Universitas Andalas (No: 160/KEP/FK/2019).

Jumlah sampel yang digunakan dalam penelitian ini adalah sebanyak 38 orang dengan kriteria inklusi pasien lakilaki dengan usia 55 - 69 tahun, PPOK stabil dan tidak bergantung kepada terapi oksigen. Pasien dengan riwayat asma dan trauma thorak akan dieksklusi dari penelitian. Pasien dipilih secara acak berdasarkan daftar nama pasien yang berada pada bulan Februari tahun 2019. Selanjutnya pasien yang telah terpilih menjadi sampel penelitian akan memilih salah satu dari 38 amplop yang telah disediakan. Pasien yang mendapat amplop berisi angka 1-19 akan masuk ke kelompok intervensi dan pasien dengan amplop 20-38 masuk ke kelompok kontrol

Pengukuran skala dispnea dilakukan dengan menggunakan MRC Dyspnea Scale dengan membagi kategori dispnea menjadi 3, skala 1 merupakan dispnea ringan, 2-3 merupakan dispnea sedang dan 4-5 merupakan dispnea berat.

Pasien yang telah menandatangani informed consent dan setuju untuk diberikan terapi selama 4 minggu. Pasien pada kelompok intervensi akan mendapat latihan pursed lip breathing, diaphragmatic breathing, dan upper limb stretching sementara pasien kelompok kontrol tidak diberikan intervensi apapun, namun pasien kelompok kontrol akan diberikan latihan setelah penelitian selesai dilakukan.

Analisis data skala dispnea pada saat pretest dan posttest disajikan dalam bentuk distribusi frekuensi. Untuk melihat perbedaan antara skala dispnea pada saat pretest dan posttest dilakukan uji beda menggunakan Wilcoxon test. 


\section{HASIL}

Selama proses penelitian berlangsung, 2 orang sampel dieksklusi dari penelitian karena mengalami kelelahan dan penurunan kondisi kesehatan (1 sampel dari kelompok intervensi dan 1 sampel dari kelompok kontrol). Perbedaan skala dispnea pada saat pretest dan posttest pada kelompok intervensi dapat dilihat pada tabel 1 dan perbedaan skala dispnea pada saat pretest dan posttest pada kelompok kontrol dapat dilihat pada tabel 2.

Tabel 1. Skala Dispnea Kelompok Intervensi pada Saat Pretest dan Posttest

\begin{tabular}{cccc}
$\begin{array}{ccc}\text { Skala } \\
\text { Dispnea }\end{array}$ & Pretest & Posttest & $\begin{array}{c}\text { p } \\
\text { value }\end{array}$ \\
\cline { 1 - 3 } Ringan & 0 & 1 & \\
\cline { 1 - 3 } Sedang & 11 & 16 & 0,008 \\
\cline { 1 - 3 } Berat & 7 & 1 & \\
\hline
\end{tabular}

Tabel 2. Skala Dispnea Kelompok Kontrol pada Saat Pretest dan Posttest

\begin{tabular}{cccc}
$\begin{array}{c}\text { Skala } \\
\text { Dispnea }\end{array}$ & Pretest & Posttest & $\begin{array}{c}\text { p } \\
\text { value }\end{array}$ \\
\cline { 1 - 3 } Ringan & 0 & 0 & \\
\cline { 1 - 3 } Sedang & 13 & 12 & 0,655 \\
\cline { 1 - 3 } Berat & 5 & 6 & \\
\hline
\end{tabular}

\section{PEMBAHASAN}

Adanya penurunan skala dispnea berat dari 7 orang pada saat pretest menjadi 1 orang pada saat posttest. Sedangkan pada kelompok kontrol terjadi peningkatan skala dispnea berat dari 5 orang pada saat pretest menjadi 6 orang pada saat posttest. Sesak nafas merupakan gejala yang sering muncul dan dianggap paling mengganggu bagi pasien PPOK (Daher et al., 2019). Menurut Mahler et al. (2017) sesak nafas pada pasien PPOK diakibatkan oleh faktor mekanis dari otototot pernapasan, peningkatan tahanan dinding dada, kurangnya asupan oksigen kedalam tubuh, gangguan pertukaran gas, hambatan pada jalan nafas, dan kelemahan dari otot-otot pernapasan. Selain itu, sesak nafas yang diakibatkan kelemahan otot pernapasan timbul akibat kurang optimalnya proses inspirasi dan ekspirasi pada pasien PPOK akibat adanya obstruksi pada jalan nafas yang mengganggu proses aliran udara keluar masuk paru-paru (McConnell, 2013).

Menurut O'Donnell et al. (2016) secara fisiologis sesak nafas yang timbul pada saat pasien PPOK melakukan aktivitas atau latihan adalah adanya peningkatan aktivitas saraf eferen inspirasi pada otot diafragma oleh bagian korteks dan bulbo-pontine pada otak, peningkatan reflek kemoreseptor dari abnormalitas proses ventilasi/perfusi alveolar dan desaturasi oksigen, dan peningkatan kontraktilitas otot inspirasi akibat penurunan daya elastisitas paru. Hal ini menimbulkan sensasi rasa kekurangan udara dan dispnea ketika melakukan aktivitas atau latihan (Marchetti \& Kaplan, 2018). Dispnea pada saat melakukan aktivitas akan menjadi salah satu faktor yang mengakibatkan menurunnya ketahanan pasien PPOK dalam melakukan aktivitas fisik dari orang normal lainnya (Andayani, Rizki, \& Lubis, 2014).

Pursed lip breathing dan pernapasan diafragma yang diberikan pada pasien PPOK dapat disertai dengan peregangan pada otot-otot tubuh bagian atas (upper limb stretching). Peregangan pada otot tubuh akan meningkatkan massa otot, kekuatan, dan ketahanan dalam melakukan aktivitas atau proses latihan fisik (Silva, Neto, Saquetto, Conceicao, \& Machado, 2018). Peregangan otot tubuh bagian atas juga mampu mengoptimalkan fungsi neuromekanik dari otot pernapasan yang menurun pada pasien PPOK (Kaymaz et al., 2018). Adanya peregangan pada otot tubuh bagian atas disertai dengan latihan pernapasan diafragma dan pursed lip breathing dapat membantu menurunkan dispnea pada saat beraktivitas sehingga meningkatkan kapasitas latihan dan ketahanan pada pasien PPOK.

Latihan pursed lip breathing memiliki beberapa manfaat bagi pasien 
PPOK. Menurut Sachdeva et al. (2014) pursed lip breathing pada pasien PPOK menurunkan hiperinflasi pada paru dengan meningkatkan tekanan intraluminal jalan nafas untuk mencegah kolaps pada paru. Pursed lip breathing juga mampu meningkatkan kecepatan aliran udara ekspirasi yang mampu mengoptimalkan proses pertukaran karbon dioksida dengan oksigen menjadi lebih cepat, sehingga mampu menurunkan sesak nafas pasien PPOK (Potdar, 2018). Proses oksigenasi dalam tubuh menjadi lebih baik dengan adanya latihan pursed lip breathing, hal tersebut dapat menjadi lebih optimal dengan meningkatkan fungsi otot-otot pernapasan, khususnya otot diafragma.

Otot diafragma merupakan salah satu otot pernapasan yang memegang peran penting dalam melakukan proses respirasi. Ma et al. (2017) mengatakan bahwa latihan pernapasan diafragma dapat menurunkan derajat dispnea dan meningkatkan ketahanan pasien PPOK dalam beraktivitas. Latihan pernapasan diafragma dapat meningkatkan aktivitas saraf frenikus yang mengkoordinasi otot diafragma melakukan inspirasi dan ekspirasi bekerja lebih optimal (Yamaguti et al., 2012). Latihan pernapasan diafragma dengan disertai pursed lip breathing meningkatkan volume dinding dada dengan meningkatkan uptake oksigen kedalam tubuh, sehingga dispnea yang dirasakan pasien PPOK akan menurun dan kapasitas dalam melakukan aktivitas fisik atau latihan dapat ditingkatkan (Ichimura et al., 2018).

Penelitian yang dilakukan oleh Sievi et al. (2018) program latihan otot pernapasan seperti IMT dapat membantu mengurangi gejala dispnea dari pasien PPOK. Pursed lip breathing, latihan pernapasan diafragma, dan peregangan otot tubuh bagian atas dapat memperbaiki proses pertukaran gas dalam paru, meningkatkan kekuatan otot diafragma saat inspirasi dan ekspirasi, dan mengoptimalkan fungsi otot pernapasan dan otot-otot bantu pernapasan (Al Karn, Hassan, Abo El Fadl, \& Mahmoud, 2018; Kang, Jeong, \& Choi, 2016; Zuwallack \& Celli, 2016). Setelah menjalani program latihan otot pernapasan, derajat dispnea yang dirasakan oleh pasien PPOK akan menurun dan mampu meningkatkan ketahanan dan kapasitas saat melakukan aktivitas atau latihan (exercise).

\section{KESIMPULAN DAN SARAN}

Kesimpulan dari penelitian ini adalah otot pernapasan pasien PPOK yang mengalami kelemahan dapat kembali dioptimalkan. Salah satu upaya dalam meningkatkan kekuatan otot pernapasan adalah dengan melakukan latihan otot pernapasan (pursed lip breathing, diaphragmatic breathing, dan upper limb stretching) secara rutin. Latihan otot pernapasan yang dilakukan secara rutin, disertai dengan gaya hidup yang sehat dapat membantu meningkatkan kemampuan aktivitas pasien PPOK dalam kehidupan sehari-hari.

\section{UCAPAN TERIMA KASIH}

Peneliti mengucapkan terima kasih yang sebesar-besarnya kepada seluruh responden yang telah berpartisipasi dan pihak rumah sakit yang telah memberikan izin untuk penelitian .

\section{DAFTAR PUSTAKA}

Al Karn, A. F., Hassan, W. A., Abo El Fadl, A. A., \& Mahmoud, M. A. (2018). Medication adherence and treatment satisfaction in some Egyptian patients with chronic obstructive pulmonary disease and bronchial asthma. Egyptian Journal of Bronchology, Vol. 12(No. 1), 33-40. https://doi.org/10.4103/ejb.ejb

Amin, A., \& Zedan, M. (2017). Transthoracic ultrasonographic evaluation of diaphragmatic excursion in patients with chronic obstructive pulmonary disease. Egyptian Journal of Bronchology, O(0), 0. 
https://doi.org/10.4103/1687-

8426.217411

Andayani, N., Rizki, M., \& Lubis, R. (2014). Hubungan Derajat Sesak Napas Penyakit Paru Obstruktif Kronik dengan Simptom Ansietas. Jurnal Kedokteran Syiah Kuala, 14(2), 92-97.

Daher, A., Matthes, M., Keszei, A., Brandenburg, V., Müller, T., Cornelissen, C., \& Dreher, M. (2019). Characterization and Triggers of Dyspnea in Patients with Chronic Obstructive Pulmonary Disease or Chronic Heart Failure: Effects of Weather and Environment. Springer Science, 197(1), 21-28. https://doi.org/10.1007/s00408-0180170-2

Heydari, A., Farzad, M., \& Ahmadi Hosseini, S. H. (2015). Comparing Inspiratory Resistive Muscle Training with Incentive Spirometry on Rehabilitation of COPD Patients. Rehabilitation Nursing, 40(4), 243248. https://doi.org/10.1002/rnj.136

Ichimura, T., Yokogawa, M., Nakagawa, T., Miaki, H., Kurebayashi, T., \& Nishino, M. (2018). Comparison of two instructions for deep breathing exercise: non-specific and diaphragmatic breathing. Journal of Physical Therapy Science, 30(4), 614-618. https://doi.org/10.1589/jpts.30.614

Kang, J., Jeong, D. K., \& Choi, H. (2016). The effects of breathing exercise types on respiratory muscle activity and body function in patients with mild chronic obstructive pulmonary disease. The Journal of Physical Therapy Science Original, 28, 500505.
Kaymaz, D., Candemir, I. C., Ergun, P., Demir, N., Tasdemir, F., \& Demir, P. (2018). Relation between upper-limb muscle strength with exercise capacity, quality of life and dyspnea in patients with severe chronic obstructive pulmonary disease. Clin Respir J, 12(5), 1257-1263. https://doi.org/10.1111/crj.12659

Langer, D., Charususin, N., Jácome, C., Hoffman, M., McConnell, A., Decramer, M., \& Gosselink, R. (2015). Efficacy of a Novel Method for Inspiratory Muscle Training in People With Chronic Obstructive Pulmonary Disease. Physical Therapy, 95(9). https://doi.org/10.2522/ptj.20140245

Ma, X., Yue, Z., Gong, Z., Zhang, H., Duan, N., \& Shi, Y. (2017). The Effect of Diaphragmatic Breathing on Attention, Negative Affect and Stress in Healthy Adults. Breathing Practice Promotes Mental Health, 8(June), 112.

https://doi.org/10.3389/fpsyg.2017.00 874

Mahler, D. A., Fierro-Carrion, G., \& Baird, J. C. (2017). Evaluation of dyspnea in the elderly. Clinics in Geriatric Medicine, 19(1), 19-33. https://doi.org/10.1016/S07490690(02)00050-2

Malini, H., Fatmadona, R., Rahman, D., \& Afriyanti, E. (2018). Buku Ajar Keperawatan Medikal Bedah I (1st ed.). Depok: PT. Rajagrafindo Persada.

Marchetti, N., \& Kaplan, A. (2018). Dyspnea and Hyperinfl ation in Chronic Obstructive Pulmonary Disease: Impact on Physical Activity. The Journal of Family Practice and Cleveland Clinic Journal of Medicine. 
Doi: $\quad$ 163(6), 3-10. https://doi.org/10.7326/m15-0288

McConnell, A. (2013). Respiratory muscle training: Theory and Practice. Churchill Livingstone Elsevier. Philadelphia: Elsevier Health Sciences UK. Retrieved from http://search.ebscohost.com/login.asp $\mathrm{x}$ ?direct $=$ true $\& \mathrm{db}=\operatorname{cin} 20 \& \mathrm{AN}=10786$ $7885 \&$ site $=$ ehost-live

Mehani, S. H. M. (2017). Comparative study of two different respiratory training protocols in elderly patients with chronic obstructive pulmonary disease. Clinical Intervention in Aging, (12), 1705-1715.

O’Donnell, D. E., Elbehairy, A. F., Faisal, A., Webb, K. A., Neder, J. A., \& Mahler, D. A. (2016). Exertional dyspnoea in COPD: the clinical utility of cardiopulmonary exercise testing. European Respiratory Review, 25(141), 333-347. https://doi.org/10.1183/16000617.005 4-2016

Potdar, S. (2018). A Comparative Study between the Effect of Breathing Control and Pursed Lip- Breathing Exercises in COPD Patients on Expiratory Flow Rate. Journal of Physiotherapy Research, 2(4), 1-3.

Russell, R. E. K., Ford, P. A., Barners, P. J., \& Russel, A. (2013). Managing COPD (3rd ed.). London: Spring Healthcae.

Sachdeva, S., Pawaria, S., \& Kalra, S. (2014). Effect of Pursed Lip Breathing and Mouth Mask on Dyspnea in Healthy Individuals- A Pilot Study. International Journal of Health Sciences and Research, 8(July), 1-3.
Sievi, N. A., Brack, T., Brutsche, M. H., Frey, M., Irani, S., Leuppi, J. D., ... Clarenbach, C. F. (2018). Physical activity declines in COPD while exercise capacity remains stable: A longitudinal study over 5 years. Elsevier, 141(June), 1-6. https://doi.org/10.1016/j.rmed.2018.0 6.013

Silva, Neto, M. G., Saquetto, M. B., Conceicao, C. S., \& Machado, A. S. (2018). Effects of upper limb resistance exercise on aerobic capacity, muscle strength, and quality of life in COPD patients: a randomized controlled trial. Clinical Rehabilitation, 32(12), 1636-1644. https://doi.org/10.1177/02692155187 87338

Tim Promosi Kesehatan Rumah Sakit (PKRS). (2017). Data Rekapan Kunjungan Kasus Penyakit Paru Poliklinik Rumah Sakit Paru Sumatera Barat Tahun 2017. Padang Pariaman.

Walters, J., Tan, D., White, C., \& WoodBaker, R. (2018). Different durations of corticosteroid therapy for exacerbations of chronic obstructive pulmonary disease (Systematic Review ). The Chocrane Collaboration, (3), 3-5. https://doi.org/10.1002/14651858.CD 006897.pub2.Copyright

World Health Organization (WHO). (2016). Chronic Obstructive Pulmonary Disease (COPD). New York. Retrieved from www.un.org/hr/roadsafety/pdf/roadsaf etyreport.pdf

Yamaguti, W. P., Claudino, R. C., Neto, A. P., Chammas, M. C., Gomes, A. C., Salge, J. M., ... Ap, N. (2012). Diaphragmatic Breathing Training Program Improves Abdominal Motion 
NERS: Jurnal Keperawatan, Volume 15, No. 2, Oktober 2019, (Hal. 103-109)

During Natural Breathing in Patients With Chronic Obstructive Pulmonary Disease: A Randomized Controlled Trial. Arch Phys Med Rehabil, 93(4), 571-577.

https://doi.org/10.1016/j.apmr.2011.1 1.026

Zuwallack, R., \& Celli, B. (2016). Pulmonary Rehabilitation. Pulmonary Rehabilitation (Sixth Edit). Elsevier Inc.

https://doi.org/10.1002/97804706976

03.ch5 